\title{
Review Article \\ Neoadjuvant Chemotherapy and Targeted Therapy in Breast Cancer: Past, Present, and Future
}

\author{
Simon P. Gampenrieder, Gabriel Rinnerthaler, and Richard Greil \\ 3rd Medical Department with Hematology, Medical Oncology, Hemostaseology, \\ Rheumatology and Infectious Diseases, Oncologic Center, Laboratory of Immunological and Molecular Cancer Research, \\ Paracelsus Medical University, Müllner Hauptstraße 48, 5020 Salzburg, Austria \\ Correspondence should be addressed to Richard Greil; r.greil@salk.at
}

Received 18 December 2012; Accepted 11 July 2013

Academic Editor: James L. Mulshine

Copyright (C) 2013 Simon P. Gampenrieder et al. This is an open access article distributed under the Creative Commons Attribution License, which permits unrestricted use, distribution, and reproduction in any medium, provided the original work is properly cited.

\begin{abstract}
Traditionally, neoadjuvant treatment for breast cancer was preserved for locally advanced and inflammatory disease, converting an inoperable to a surgical resectable cancer. In recent years, neoadjuvant therapy has become an accepted treatment option also for lower tumor stages in order to increase the rate of breast conserving therapy and to reduce the extent of surgery. Furthermore, treatment response can be monitored, and therefore, patient compliance may be increased. Neoadjuvant trials, additionally, offer the opportunity to evaluate new treatment options in a faster way and with fewer patients than large adjuvant trials. Compared to the metastatic setting, the issue of acquired resistance and pretreatments, which may distort treatment efficacy, can be avoided. New trial designs like window-of-opportunity trials or postneoadjuvant trials provide the chance to identify tumor sensitivity or to overcome tumor resistance in early tumor stages. In particular, in HER2-positive breast cancer, the neoadjuvant approach yielded great successes. The dual HER2 blockade with trastuzumab and pertuzumab recently showed the highest pCR rates ever reported. Many new drugs are in clinical testing with the aim to further increase pCR rates. Whether this endpoint really represents a surrogate for long-term outcome is not answered yet and will be discussed in this review.
\end{abstract}

\section{Introduction}

In recent years, there has been a growing interest in the neoadjuvant approach for early breast cancer. Compared to the classical adjuvant treatment, it offers several advantages. First, it provides the opportunity to monitor response during treatment and allows changing or discontinuing treatment in case of nonresponsiveness. Even if an advantage by changing therapy has not yet been proven, toxicity of an ineffective treatment can be avoided. The demonstration of treatment efficacy, conversely, motivates patients to continue therapy despite toxicities. Second, the rate of breast conservation can be increased, and in case of breast conserving therapy (BCT), the extent of surgery can be reduced. Additionally, primarily inoperable tumors can be downsized allowing a curative intervention. Third, the residual cancer burden (RCB) is a powerful prognostic marker, sometimes changing the initial prognostic profile in either way. Forth, in neoadjuvant trials predictive markers, tumor biology, mechanisms of resistance, and new treatment approaches can be investigated more rapidly and with fewer patients than in adjuvant studies.

In the following sections, we give an overview of the historical background which is the basis for current treatment and research strategies. We discuss context and data of recent trials and give a perspective to future developments.

\section{Neoadjuvant versus Adjuvant}

In the early nineties, neoadjuvant and adjuvant therapies were first compared in randomized trials, using the same chemotherapeutic regimen pre- and postoperatively. The initial intention was to improve long-term outcome in patients with large but potentially operable breast cancer due to an earlier exposure to systemic therapy. The largest and most important trial was the National Surgical Adjuvant Breast and Bowel Project (NSABP) B-18 trial which compared 4 cycles of doxorubicin plus cyclophosphamide (AC) given either preoperatively or postoperatively. In total, 1,523 women with 
a median tumor size of $3.5 \mathrm{~cm}$ were included independent of hormone receptor status. In the neoadjuvant arm, the objective clinical response (ORR) rate was $78 \%$ with clinical partial response (cPR) in $43 \%$ and a clinical complete response (cCR) in 36\%. A pathologic complete response (pCR) was documented in $13 \%$ of patients. The two main findings in NSABP B-18 however were (1) no difference in overall survival $(\mathrm{HR}=0.99 ; 95 \% \mathrm{CI}, 0.85$ to $1.16 ; P=.90)$ and diseasefree survival $(\mathrm{HR}=0.93 ; 95 \% \mathrm{CI}, 0.81$ to $1.06 ; P=.27)$ between pre- and postoperative chemotherapy; (2) patients achieving a pCR had a superior DFS and OS compared to patients not achieving a pCR (DFS: $\mathrm{HR}=0.47, P<.0001$; OS: $\mathrm{HR}=0.32, P<.0001)$. Furthermore, there was a trend in favor of neoadjuvant chemotherapy compared with adjuvant therapy for OS and DFS in women younger than 50 years (OS: $\mathrm{HR}=0.81, P=.06$; DFS: $\mathrm{HR}=0.85, P=.09)[1]$.

Similar results were shown in the EORTC trial 10902 where 698 patients (T1c-T4b, N0-1, M0, ER positive and negative) were randomly assigned to 4 cycles of fluorouracil, epirubicin, and cyclophosphamide (FEC) administered preoperatively versus the same regimen given postoperatively. There was no difference in terms of PFS, OS, or local recurrence rate ( $\mathrm{HR} 1.15, P=.27$; $\mathrm{HR} 1.16, P=.38$; and $\mathrm{HR}$ $1.13, P=.61$, resp.) [2]. Nine randomized studies comparing neoadjuvant with adjuvant treatment were pooled in a metaanalysis including a total of 3,946 patients. Similar to the previously mentioned phase-III trials, Mauri and colleagues found no difference with regard to death (RR 1.00, 95\% CI, 0.90 to 1.12 ), disease progression ( $\mathrm{RR} 0.99,95 \% \mathrm{CI}, 0.91$ to 1.07 ), or distant disease recurrence (RR $0.94,95 \% \mathrm{CI}, 0.83$ to 1.06). However, the rate of local recurrence was higher in the neoadjuvant group (RR 1.22, 95\% CI, 1.04 to 1.43 ). This was mainly caused by trials in which surgery was avoided in case of clinical complete response [3].

Nonetheless, for an individual patient, the delay of surgery by preoperative therapy could provide potential harm. Given that all randomized trials are comparisons of cohorts, the disadvantages of single patients are not reflected in the overall results. Fortunately, the proportion of tumors progressing during neoadjuvant therapy is very low, but hypothetically even if the tumor as a whole is shrinking, single tumor cells could respond differentially. As discussed elsewhere, partly resistant tumor cells might acquire fullblown resistance during neoadjuvant treatment and generate micrometastases [4].

In summary, the primary objective to show an advantage due to earlier systemic therapy was not met, but it has been shown that neoadjuvant chemotherapy is as effective as adjuvant chemotherapy. Additionally, the rate of breast conservation in operable disease can be increased, even if the risk of local recurrence might be slightly higher.

The results of trials comparing neoadjuvant with adjuvant chemotherapy are summarized in Table 1.

\section{Addition of Taxanes}

The rate of pCR in these early trials was quite low with a range from 4 to $29 \%$. Therefore, the addition of taxanes to the classical anthracycline-based chemotherapy was investigated in several phase-III trials. In 2002, first results from the Aberdeen trial $(n=162)$ were reported, where 4 cycles of cyclophosphamide, doxorubicin, vincristine and prednisolone (CVAP) followed by four cycles of docetaxel were compared with eight cycles of CVAP. All clinical endpoints were better in the taxane containing arm, including a higher rate of clinical response (66 versus $94 \%, P=.001$ ), pCR (15 versus $31 \%, P=.06$ ), an improved 5-year OS (78 versus $93 \%, P=.04$ ) and 5 -year DFS (72 versus $90 \%$, $P=.04$ ), and a higher rate of BCT (49 versus 67\%) [5]. In contrast, in the large NSABP $B-27$ trial, the addition of docetaxel showed no difference in DFS, OS, and rate of BCT. Here, a total of 2,411 patients were randomized between 4 cycles of doxorubicin/cyclophosphamide (arm 1), the same schedule followed by 4 cycles of docetaxel preoperatively (arm 2) or postoperatively (arm 3). Patients in arm 2 had a higher clinical (64\%) and pathological complete response rate (26\%) than patients in arms 1 and 3 (40\% and 14\%, resp.). Additionally, a trend towards longer relapse-free survival (RFS) was observed for arm 2 in comparison with arm 1 (5-year RFS: 74 versus 70\%, HR 0.85; 95\% CI, 0.71 to 1.02 ). Again, pCR was a highly significant surrogate marker for better outcome [1]. Seven randomized trials including 2,455 patients were summarized in a literature-based meta-analysis in order to answer the question if the addition of taxanes to an anthracyclines-based chemotherapy provides an advantage in the primary treatment for early breast cancer. The rate of BCT was significantly higher for patients receiving taxanes, with an absolute difference $(\mathrm{AD})$ of $3.4 \%(P=.012)$. The rate of pCR was higher for patients receiving taxanes, but only statistically significant if used in a sequential schedule with an $\mathrm{AD}$ of $2.4 \%(P=.013)$ [6].

The results of randomized trials incorporating either concurrent or sequential taxane-based neoadjuvant therapy are summarized in Table 2.

\section{Addition of Other Chemotherapeutics}

Beside taxanes, several other chemotherapeutics were added to neoadjuvant regimens to further improve $\mathrm{pCR}$ rate. In the TOPIC trial, the efficacy of continuous infusional 5fluorouracil for 18 weeks and the integration of cisplatin were investigated. In comparison to 6 cycles of doxorubicin plus cyclophosphamide, no difference in response rate (75 versus $77 \%, P=.6)$, pCR rate (16 versus $16 \%, P=1.0$ ), or long-term outcome (5-year OS 82 versus $74 \%, P=.18$ ) could thereby be shown. Infusional 5-FU, however, was associated with a higher rate of grade 3 toxicities [7]. Similar results were shown in the TOPIC-II trial investigating epirubicin plus vincristine versus standard AC without improving any of the endpoints (cORR, pCR, BCT, DFS, and OS) [8]. Negative results were also found for gemcitabine investigated in the Neo-tAnGo and the NSABP B-40 trials $[9,10]$. For capecitabine, available data are contradictory: in the ABCSG-24 study, the addition of capecitabine to 6 cycles of epirubicin plus docetaxel improved the pCR rate $(24$ versus $16 \%, P=.02)$ [11], while in the NSABP B-40 and GeparQuattro trials no differences in 
TABLE 1: Trials comparing the same chemotherapeutic regimen pre- and postoperatively.

\begin{tabular}{|c|c|c|c|c|c|c|}
\hline Trial & Phase $(n)$ & Tumors & NA versus adjuvant & Primary endpoint & Other outcomes & Ref. \\
\hline IBBGS & III (272) & $\begin{array}{l}\mathrm{T} 2>3 \mathrm{~cm} \\
\text { or T3 N0-1 }\end{array}$ & $3 \times \mathrm{EVM} \rightarrow 3 \times \mathrm{ETV}$ & $\begin{array}{l}\text { BCT } 63 \% \text { ( } 33 \% \text { RT only, } 30 \% \text { S } \\
+ \text { RT) versus } 0 \%\end{array}$ & $\begin{array}{l}\text { No difference in DFS or OS; } \\
34 \% \text { local recurrence with RT } \\
\text { only }\end{array}$ & {$[40,41]$} \\
\hline Institut Curie S6 & III (390) & T2-3, N0-1 & $4 \times \mathrm{FAC}$ & $\begin{array}{l}\text { BCT } 82 \text { versus } 77 \% \text { (ns) } \\
\text { (S only if no cCR after RT) }\end{array}$ & $\begin{array}{l}\text { No difference in DFS and OS, } \\
\text { short-term OS benefit }(P=.02) \\
\text { for NA }\end{array}$ & {$[42,43]$} \\
\hline Royal Marsden & III (293) & T0-4, N0-1 & $4 \times 2 \mathrm{MT}$ & BCT 89 versus $78 \%(P=.004)$ & $\begin{array}{l}\text { No difference in DFS, OS, and } \\
\text { local recurrence; pCR 7\% }\end{array}$ & {$[44,45]$} \\
\hline NSABP B-18 & III (1493) & T1-3, N0-1 & $4 \times \mathrm{AC}$ & $\begin{array}{l}5 \text { y-OS: } 80 \text { versus } 81 \%(n s) \\
5 \text { y-DFS: } 67 \text { versus } 67 \%(n s)\end{array}$ & $\begin{array}{l}\text { BCT } 68 \text { versus } 60 \%(P=.001) ; \\
\text { LRR } 13 \text { versus } 10 \%(P=.21) ; \\
\text { ORR } 78 \% \text {, pCR } 13 \% \text {; } \\
\text { pCR associated with better } \\
9 \text { y-DFS ( } 75 \text { versus } 58 \%) \\
\text { pCR associated with better } \\
9 \text { y-OS ( } 85 \text { versus } 73 \%) ; \\
\text { trends in favor of NA for DFS } \\
\text { and OS in women }<50 y\end{array}$ & $\begin{array}{c}{[1,46,} \\
47]\end{array}$ \\
\hline EORTC 10902 & III (698) & $\mathrm{T} 1 \mathrm{c}-\mathrm{T} 4 \mathrm{~b}$ & $4 \times \mathrm{FEC}$ & $\begin{array}{l}4 \mathrm{y} \text {-OS } 82 \text { versus } 84 \% \\
(P=.38)\end{array}$ & $\begin{array}{l}4 \text { y-PFS } 65 \text { versus } 70 \%(P=.27) \text {; } \\
\text { LRR } 5 \text { versus } 5 \%(n) \text {; } \\
\text { pCR } 4 \% \text {; } \\
\text { downstaging to BCT in } 23 \%\end{array}$ & {$[2]$} \\
\hline ABCSG-7 & III (423) & $\begin{array}{l}\text { T1-3, N0-1 } \\
\text { HR- + high } \\
\text { risk HR+ }\end{array}$ & $3 \times \mathrm{CMF}$ & $\begin{array}{l}\text { RFS better with adjuvant } \\
\text { therapy (HR } 0.7 ; P=.02) \text {; } \\
\text { no difference in OS (HR } 0.8 \text {; } \\
P=.21 \text { ) }\end{array}$ & $\begin{array}{l}\text { cORR } 56 \% \text {, pCR 6\%; } \\
\text { LRR } 13 \text { versus } 8 \%(P=.1)\end{array}$ & {$[48]$} \\
\hline Meta-analysis & IV (3946) & $\begin{array}{l}9 \\
\text { randomized } \\
\text { trials }\end{array}$ & Same regimen & $\begin{array}{l}\text { No difference in OS (RR 1.0); } \\
\text { no difference in DFS (RR 0.99) }\end{array}$ & $\begin{array}{l}\text { LRR higher for NA (RR } 1.22 \text {; } \\
P=.015 \text { ) especially if no } S \text { was } \\
\text { done; } \\
\text { pCR range } 4-29 \%\end{array}$ & {$[3]$} \\
\hline
\end{tabular}

EVM: epirubicin, vincristin, methotrexat; ETV: mitomycin, thiotepa, vindesine; FAC: 5-FU, doxorubicin, cyclophosphamide; 2MT: mitoxantrone, methotrexat, tamoxifen; AC: doxorubicin, cyclophosphamide; FEC: 5-FU, epirubicin, cyclophosphamide; CMF: cyclophosphamide, methotrexat, 5-FU.

pCR rates were observed. In NSABP B-40, capecitabine was administered for 3 cycles in addition to docetaxel followed by $\mathrm{AC}[10]$ and in GeparQuattro capecitabine was given in combination or sequentially to docetaxel after 4 cycles of $\mathrm{AC}$ [12]. The longer administration of capecitabine (6 versus 4 cycles) and the missing alkylating agent in ABCSG-24 are two potential explanations for these differences. Based on these results, neither capecitabine nor 5-FU, cisplatin, vinorelbine, or gemcitabine can be considered as standard neoadjuvant therapy in operable breast cancer.

\section{PCR as a Prognostic Marker and as a Surrogate for Long-Term Outcome}

In many neoadjuvant trials, patients achieving a pCR showed a better long-term outcome, indicating $\mathrm{pCR}$ as a strong prognostic marker $[1,13]$. This is particularly true if both breast and lymph nodes are free of invasive carcinoma. The influence of residual intraductal disease (DCIS) on prognosis is not yet totally clear. In a retrospective analysis of 2,302 breast cancer patients treated in a neoadjuvant setting at the MD Anderson, 3.4\% had pCR in breast and lymph nodes and $8.6 \%$ had residual DCIS. There was no difference in terms of 10 -year DFS rates ( 81 versus $82 \%$ ), 10-year OS rates (92 versus
93\%), and locoregional RFS rates (93 versus 91\%) [14]. In contrast, a pooled analysis of 7 randomized trials conducted by the German Breast Group (GBG) including 6,377 patients showed a small but significant difference in DFS between patients without any residual disease (ypT0/N0) and patients with remaining DCIS (ypTis ypN0) (HR 1.74; 95\% CI, 1.28 to 2.36; $P=.001)$. In addition, a trend towards better OS was shown (HR 1.41; 95\% CI, 0.87 to 2.29; $P=.166$ ) [15]. The same analysis demonstrated that in luminal $\mathrm{A}$ and luminal B (ER plus HER2 positive) tumors, pCR is not associated with prognosis, whereas in patients with highly proliferating carcinomas like triple negative breast cancer (TNBC) or HER2 enriched tumors (HER2 positive plus ER negative), pCR can accurately discriminate between good and poor prognosis [15].

The prognostic value of $\mathrm{pCR}$ for an individual patient has to be distinguished from the value of $\mathrm{pCR}$ as a surrogate for long-term outcome in neoadjuvant trials. This precondition is however crucial, because PCR is the primary endpoint of almost all neoadjuvant trials. At best, an advantage in pCR rate should translate into better DFS and OS. This has been perfectly proven in the NOAH trial where the addition of trastuzumab not only showed a higher $\mathrm{pCR}$ rate in the breast (ypTis/Nx: 43 versus $22 \%, P=.0007$ ) but also a significantly 
TABLE 2: Randomized trials incorporating either concurrent or sequential taxane-based neoadjuvant therapy.

\begin{tabular}{|c|c|c|c|c|c|c|}
\hline Trial & Phase $(n)$ & Tumors & Treatment & Primary endpoint & Other outcomes & Ref. \\
\hline $\begin{array}{l}\text { Aberdeen } \\
\text { trial }\end{array}$ & III (162) & $\geq 3 \mathrm{~cm}$ & $\begin{array}{l}4 \times \mathrm{CVAP} \rightarrow \mathrm{PR} / \mathrm{CR}: \\
4 \times \mathrm{CVAP} \text { versus } 4 \times \\
\mathrm{Doc} ; \mathrm{SD} / \mathrm{PD}: 4 \times \text { Doc }\end{array}$ & pCR 16 versus $34 \% ; P=.04$ & $\begin{array}{l}\text { cORR } 66 \text { versus } 94 \%, P=.001 ; \\
\text { BCT } 48 \text { versus } 67 \% ; \\
5 y \text {-OS }(78 \text { versus } 93 \%, P=.04) ; \\
5 \text { y-DFS ( } 72 \text { versus } 90 \%, P=.04)\end{array}$ & {$[49,50]$} \\
\hline NSABP B-27 & III (2411) & $\begin{array}{l}\text { T1c-3 N0, } \\
\text { T1-3 N1; } \\
\text { (median } \\
9 \mathrm{~cm})\end{array}$ & $\begin{array}{l}4 \times \mathrm{AC} \rightarrow \mathrm{S} \text { versus } \\
4 \times \mathrm{AC} \rightarrow 4 \times \mathrm{Doc} \\
\rightarrow \mathrm{S} \text { versus } 4 \times \mathrm{AC} \\
\rightarrow \mathrm{S} \rightarrow 4 \times \mathrm{Doc}\end{array}$ & $\begin{array}{l}\text { DFS (arm } 2 \text { versus } 1) \text { HR } 0.92 \\
(P=.29) ; \\
\text { OS }(P \text { across all } 3 \text { arms }=.76) \\
\text { RFI }(\text { arm } 2 \text { versus } 1: \text { HR } 0.83 \\
P=.04)\end{array}$ & $\begin{array}{l}\text { LRR }(\operatorname{arm} 2 / 3 \text { versus } 1) \text { HR } 0.67 \\
(P=.02) ; \\
\text { BCT } 62 \text { versus } 64 \%(\mathrm{~ns}) \\
\text { ORR } 86 \text { versus } 91 \%(P<.001) ; \\
\text { pCR } 9 \text { versus } 19 \%(P=.0001) \\
\text { pCR associated with better DFS } \\
\text { (HR } 0.49, P<.0001) \text { and OS } \\
\text { (HR } 0.36, P<.0001)\end{array}$ & $\begin{array}{c}{[1,51,} \\
52]\end{array}$ \\
\hline ACCOG & III (363) & $\geq 3 \mathrm{~cm}$ or $\mathrm{T} 4 \mathrm{~d}$ & $\begin{array}{c}6 \times \mathrm{AC} \text { versus } \\
6 \times \mathrm{ADoc}\end{array}$ & $\begin{array}{l}\text { pCR } 24 \text { versus } 21 \%(P=.61) ; \\
\text { cORR } 61 \text { versus } 70 \%(P=.06)\end{array}$ & $\begin{array}{l}\text { No difference in RFS }(P=17) \text {; } \\
\text { no difference in OS }(P=.57)\end{array}$ & {$[53]$} \\
\hline Diéras et al. & III (200) & T2-3 N0-1 & $\begin{array}{c}4 \times \text { APac versus } 4 \times \\
\text { AC }\end{array}$ & pCR 16 versus $10 \%(P=\mathrm{NA})$ & $\begin{array}{l}\text { cORR } 89 \text { versus } 70 \% ; \\
\text { BCT } 58 \text { versus } 45 \% \text {; } \\
\text { DFS (18 MO: } 87 \text { versus } 79 \%) ; \\
\text { pCR associated with better DFS } \\
\text { ( } 31 \text { MO: } 91 \text { versus } 70 \%)\end{array}$ & {$[54]$} \\
\hline Meta-analysis & IV (2455) & $\begin{array}{l}7 \text { randomized } \\
\text { trials }\end{array}$ & $\begin{array}{l}\text { Anthracycline-based } \\
\text { therapy } \pm \text { taxane }\end{array}$ & $\begin{array}{l}\text { pCR better with sequential } \\
(\mathrm{RR} 1.73, P=.013) \text {, but not } \\
\text { with concomitant taxanes (RR } \\
1.04, P=.77) \text {; } \\
\text { BCT higher with taxanes (RR } \\
1.11, P=.012)\end{array}$ & $\begin{array}{l}\text { No difference in DFS (RR 0.91, } \\
P=.12 \text { ) }\end{array}$ & {$[6]$} \\
\hline
\end{tabular}

CVAP: cyclophosphamide, vincristin, doxorubicin, prednisone; Doc: doxetaxel; AC: docorubicin, cyclophosphamide; Pac: paclitaxel.

higher 3-year event-free survival (EFS) (71 versus 56\%, $P=$ .013) [16]. In contrast, the addition of docetaxel to AC in NSABP B-27 led to higher pCR (ypTis/N0) rates but did not influence DFS or OS [1]. The lack of correlation might be explained by the inclusion of low proliferative subtypes where pCR is not only rare but even unassociated with survival.

The question whether pCR really displays a reliable surrogate endpoint to replace survival data cannot be finally answered yet. The FDA has now initiated a pooled analysis of over 12,000 patients treated in different clinical trials to answer this question and to allow accelerated approval procedures for therapeutics showing a significant improvement in pCR rate in high risk operable breast cancer.

\section{Response-Adapted Therapy}

In contrast to adjuvant therapy, preoperative treatment allows to monitor response in breast and lymph nodes and gives the opportunity to discontinue or change treatment in case of nonresponsiveness. This approach was investigated in two large phase-III trials by the GBG. Both trials used ultrasound to assess treatment response. This is crucial, because clinical assessment by palpation frequently overestimates treatment response [17].

The GeparTrio trial evaluated the impact of adapting therapy after 2 cycles of docetaxel/doxorubicin/cyclophosphamide (TAC) depending on response. In case of nonresponsiveness, defined as sonographic reduction in the product of the two largest perpendicular diameters by less than $50 \%$, patients were randomly assigned to receive either further 4 cycles of TAC (standard arm) or 4 cycles of vinorelbine/capecitabine (NX, response guided arm). Responders were randomized between further 4 (standard arm) and further 6 cycles of TAC (response guided arm), respectively. Interestingly, response-adapted therapy did not change pCR rate $(6 \mathrm{x}$ versus $8 \mathrm{x}$ TAC: 21 versus $24 \%, P=.27$; $6 \mathrm{x}$ TAC versus TAC-NX: 5 versus $6 \%, P=.73)$; however, it prolonged DFS and OS significantly (6x TAC versus $8 \mathrm{x}$ TAC/TAC-NX: HR $0.71,95 \%$ CI, 0.60 to 0.85 and HR $0.79,95 \%$ CI, 0.63 to 0.99 , resp.). In particular, the hormone receptor positive subgroup had a benefit from response-guided therapy [18]. This fact could potentially explain the lack of correlation between pCR rate and survival, because, as previously mentioned, $\mathrm{pCR}$ rate is no good surrogate parameter in slowly proliferating tumors.

In GeparQuinto, the HER2 negative subgroup not responding to 4 cycles of epirubicin plus cyclophosphamide (EC) with or without bevacizumab was randomized to receive weekly paclitaxel plus everolimus or paclitaxel alone. The addition of everolimus did not change pCR rate (3.6 versus $5.6 \%, P=.48$ ) but resulted in higher toxicity rates [19]. Before drawing definite conclusions, long-term results have to be awaited, because as indicated by GeparTrio, pCR may not be the appropriate endpoint.

Altogether, both trials showed that the pCR rates are low in patients not responding to the initial 2 to 4 cycles of chemotherapy and this could not be improved by changing the regimen. Nonetheless, response-guided therapy is 
a promising approach to optimize and individualize treatment for early breast cancer. An overview of the mentioned trials is given in Table 3 .

\section{Dose-Dense and Dose-Intensified Chemotherapy}

Adjuvant as well as neoadjuvant trials tried to increase efficacy by shortening cycle intervals or by intensifying treatment dose. In the GeparDuo trial, dose-dense doxorubicin plus docetaxel was inferior to doxorubicin plus cyclophosphamide followed by docetaxel in respect to pCR rate [20]. Similarly, the SWOG 0012 study, comparing a 15week dose-dense regimen of weekly doxorubicin plus oral cyclophosphamide, did not show any difference in pCR rate, DFS or OS [21].

In contrast, the AGO-1, conducted by the GBG, showed a significant improvement in pCR rate (18 versus $10 \%, P=$ .008 ), DFS (HR 0.71, $P=.011$ ), and OS (HR 0.83, $P=$ .041) when giving sequential epirubicin and paclitaxel in a dose-dense and dose-intensified manner compared with conventionally dosed concurrent epirubicin and paclitaxel. All patients received 3 cycles of CMF postoperatively [22]. With a very similar design, the PREPARE trial tried to increase response by applying CMF preoperatively instead of postoperatively. In fact, the pCR rate was better in the dosedense and dose-intensified arm (19 versus 13\%, $P=.043)$, but without translating in a better DFS or OS (HR 1.14 and 1.26, resp.). The triple negative subgroup seemed to benefit most from intensively dosed chemotherapy even if not statistically significant (pCR: 45 versus $31 \%, P=.12$ ) [23, 24]. This observation was confirmed in a pooled analysis of 7 trials of the GBG [25].

In general, dose-dense or dose-intensified treatment is associated with a higher incidence of grade 3/4 toxicities, even if febrile neutropenia can effectively be avoided by the use of G-CSF support. Notably, the incidence of secondary acute myeloid leukemia (AML) and myelodysplastic syndrome (MDS) is strongly correlated with dose intensity and could even be raised by the use of G-CSF [26]. Although the cumulative incidence is generally low $(0.27-0.5 \%[26,27])$, such long-term effects might negatively influence survival after neoadjuvant treatment. This applies similarly to cardiotoxicity.

Therefore, and because of the modest impact on disease recurrence and OS in an unselected population, the dosedense strategy cannot be recommended outside of clinical trials. Further studies are needed not only to define the optimal regimen but also to specify the patient population with the greatest benefit from dose-dense strategy (Table 4).

\section{Targeting Her2}

8.1. Trastuzumab. The first neoadjuvant phase-III trial investigating trastuzumab in combination with chemotherapy was prematurely terminated because of the impressive superiority of the experimental arm [28]. This success story was continued by the NOAH trial, which showed a significant improvement both in terms of pCR rate (43 versus $22 \%$, $P=.0007$ ) and in 3-year event-free survival (71 versus $56 \%$, $P=.013$ ) by the addition of trastuzumab to 3 cycles of doxorubicin plus paclitaxel, followed by 4 cycles of paclitaxel alone, and followed by 3 cycles of CMF [16]. A similar rate of pCR was achieved in a phase-II trial called TECHNO, where trastuzumab was added to 4 neoadjuvant cycles of paclitaxel following 4 cycles of EC [29]. Out of 1,509 participants treated in the GeparQuattro trial, 445 had HER2-positive tumors and received trastuzumab concomitantly to docetaxel or docetaxel plus capecitabine. The pCR rate in breast and axilla (ypT0/N0) differed significantly from HER2-negative tumors (32 versus $16 \%, P<.001$ ) without influencing the rate of BCT [30].

8.2. Lapatinib. The subsequently conducted trials (NeoALLTO, CherLob, NSABP-B41, and GeparQuinto) compared the efficacy of the antibody trastuzumab with the one of the small molecule lapatinib [31-34]. Except GeparQuinto, none of them showed any difference in the pCR rate between both single agents. Lapatinib, however, was more toxic, mainly due to diarrhea (grade $3 / 4$ in $12-36 \%$ ). In the HER2positive part of GeparQuinto, trastuzumab showed higher pCR rates than lapatinib (30 versus $23 \%, P=.04$ ) [34]. Neo-ALLTO, CherLob, and NSABP-B41 included each an arm where both compounds were combined. In all three trials the combination arm demonstrated higher efficacy than both comparative arms, although results in the NSABP trial were not statistically significant. Trastuzumab plus lapatinib in combination with chemotherapy led to pCR rates above $50 \%$, without showing relevant cardiac safety issues [31-33].

This dual HER2 blockade might be the new standard in the neoadjuvant treatment of HER2-positive breast cancer, but until now, no survival data are available, and lapatinib is not approved for this indication. Similarly to the adjuvant ALLTO trial, the targeted therapy in Neo-ALLTO proceeds for a total of one year postoperatively. Thereby, long-term outcome shall be improved, particularly in case of non-pCR.

8.3. Pertuzumab. Pertuzumab is a monoclonal antibody blocking dimerization of HER2 with other members of the ERB-family like HER1, HER3, and HER4 as well as homodimerization. In the phase-II NeoSphere trial, 417 patients with HER2-positive breast cancer $(\geq 2 \mathrm{~cm})$ were randomized to 4 treatment arms each compromising 4 cycles: (A) docetaxel plus trastuzumab, (B) docetaxel plus trastuzumab plus pertuzumab, (C) trastuzumab plus pertuzumab without chemotherapy, and (D) docetaxel plus pertuzumab. The highest pCR rate, which was the primary endpoint, was attained in arm (B) with $46 \%$, being significantly better than $\operatorname{arm}(\mathrm{A})$ and (D) with $29 \%$ and $24 \%(P=.0141$ and $P=$ $.003)$, respectively. The chemotherapy-free arm showed an impressive pCR rate of $17 \%$ [35].

In TRYPHAENA, another phase-II trial, the combination of pertuzumab and trastuzumab was given in all three experimental arms: in arm (A) together with FEC followed by docetaxel, in arm (B) concomitantly to docetaxel following FEC and in arm (C) together with docetaxel and carboplatin. 
TABLE 3: Trials investigating response-adapted therapy.

\begin{tabular}{|c|c|c|c|c|c|c|}
\hline Trial & Phase $(n)$ & Tumors & Treatment & Primary endpoint & Other outcomes & Ref. \\
\hline $\begin{array}{l}\text { GeparTrio } \\
\text { pilot }\end{array}$ & II (285) & $\geq 2 \mathrm{~cm}$ & $\begin{array}{c}2 \times \text { TAC } \rightarrow \\
\text { PR/CR: } 4 \times \text { TAC; } \\
\text { SD: } 4 \times \text { TAC versus } 4\end{array}$ & pCR 23 versus 7 versus 3\% & $\begin{array}{l}\text { BCT } 72 \% \text {; pCR } 57 \%<40 \text { y with } \\
\text { TNBC or G3) }\end{array}$ & {$[55]$} \\
\hline
\end{tabular}

\begin{tabular}{|c|c|c|c|c|c|c|}
\hline GeparTrio & III (2012) & $\begin{array}{c}\text { T2-4 N0-3 } \\
\text { (except T2 + } \\
\text { ER/PR pos. }+ \\
\text { cN0 + G1/2+ } \\
\quad>35 \mathrm{y})\end{array}$ & $\begin{aligned} & 2 \times \text { TAC } \rightarrow \\
& \text { PR/CR: } 4 \text { versus } 6 \times \\
& \text { TAC; } \\
& \text { SD: } 4 \times \text { TAC versus } 4 \\
& \quad \times \text { NX }\end{aligned}$ & $\begin{array}{l}\text { pCR } 6 \text { versus } 8 \times \text { TAC: } 21 \\
\text { versus } 24 \%(P=.27) ; \\
\text { pCR TAC versus NX: } 5 \\
\text { versus } 6 \%(P=.73)\end{array}$ & $\begin{array}{l}\text { cORR } 6 \text { versus } 8 \times \text { TAC: } 75 \text { versus } \\
74 \%(n) \text {; } \\
\text { cORR TAC versus NX: both } 51 \%(P \\
\text { for noninferiority }=.008) \text {; } \\
\text { BET } 68 \text { versus } 59 \%(P=.001) \text {; } \\
\text { NX less toxic; } \\
\text { PFS } 6 \text { versus } 8 \times \text { TAC versus } \\
\text { TAC-NX: HR } 0.71(P=.001) \text {; } \\
\text { OS } 6 \text { versus } 8 \times \text { TAC versus } \\
\text { TAC-NX: HR } 0.79(P=.048) \\
\text { Benefit of response-guided therapy } \\
\text { derives from HR+ tumors (no } \\
\text { benefit for HER2+/HR- and } \\
\text { TNBC) }\end{array}$ & $\begin{array}{c}{[18,56-} \\
58]\end{array}$ \\
\hline $\begin{array}{l}\text { GeparQuinto } \\
\text { (HER2 } \\
\text { negative) }\end{array}$ & III (403) & $\begin{array}{c}\text { cT3/4; } \\
\text { cT2 if } \mathrm{HR}-\text { or } \\
\text { cN+; } \\
\text { cT1 if } \mathrm{HR}-\text { or } \\
\text { SLN+ }\end{array}$ & $\begin{array}{c}4 \times \mathrm{EC} \pm \mathrm{Bev} \rightarrow \\
\text { SD: } 12 \times \mathrm{Pac} \pm \operatorname{Rad} 001\end{array}$ & pCR 4 versus $6 \%(P=.48)$ & $\begin{array}{l}\text { CORR } 52 \text { versus } 62 \% \text {; } \\
\text { toxicity higher in the everolimus } \\
\text { group }\end{array}$ & [19] \\
\hline
\end{tabular}

TAC: docetaxel, doxorubicin, cyclophosphamide; Pac: paclitaxel; NX: vinorelbine, capecitabine; EC: epirubicin, cyclophosphamide; Bev: bevacizumab; Rad001: everolimus.

All three arms showed promising pCR rates of about $60 \%$ regardless of the chemotherapy chosen. Additionally, pertuzumab offers a favorable safety profile with neutropenia and drug hypersensitivity being the only grade $3 / 4$ toxicities reported in the chemotherapy free-arm (0.9 and 1.9\%, resp.). Even in combination with trastuzumab, no relevant changes in the left ventricular ejection fraction during neoadjuvant treatment were observed [36].

These promising phase-II data have now to be confirmed in larger phase-III trials, and long-term data have to be awaited. The results of the adjuvant trial Aphinity investigating the addition of pertuzumab to a trastuzumabchemotherapy combination will also be of high interest. An overview of the most important neoadjuvant phase-III trials in HER2 positive cancer is given in Table 5.

\section{Targeting VEGF}

Two neoadjuvant trials with bevacizumab were published simultaneously in the New England Journal of Medicine: GeparQuinto (HER2 negative part) and NSABP B-40 [10, 37]. Both phase-III trials showed a statistically significant benefit in terms of pCR rate by the addition of bevacizumab (18 versus $15 \%, P=.04$ and 35 versus $28 \%, P=.02$, resp.). Unfortunately, in the two studies, the subgroups with the greatest benefit from adding an antiangiogenic agent were different. In GeparQuinto, TNBC showed a more pronounced effect; in the NSABP trial, it was the hormone receptor-positive subgroup. Some potential explanations for this disparity are (1) that in GeparQuinto hormone receptor positive tumors were included only if they were also clinically node positive, (2) that the number of treatment cycles differed and (3) that in NSABP B-40 a lower dose of docetaxel was given due to the combination with gemcitabine or capecitabine. It is worth mentioning that the NSAPB examines the postoperative continuation of bevacizumab for 10 cycles. However, a press release already announced that BEATRICE, investigating bevacizumab in the adjuvant setting, failed to reach its primary endpoint.

Neoadjuvant bevacizumab in combination with chemotherapy could become a new standard for Her2 negative breast cancer if the improvement of $\mathrm{pCR}$ can be translated in an improvement of long term outcome and if predictive markers can be found to reduce the number needed to treat.

\section{Future Directions}

A great number of well-known and new substances are in clinical testing in phase-II and phase-III trials. The goals of these trials are not only to improve pCR rates and survival but also to individualize therapy and to reduce toxicity. By combining chemotherapy with targeted therapy, primary or secondary resistance may be avoided. Dual, triple, or multiple simultaneous targeting will soon enter the clinic, probably allowing chemotherapy-free therapies for a certain subgroup of patients. To achieve this goal, the identification of predictive markers to determine patients with maximal benefit from a certain compound is of urgent need. This is particularly true for bevacizumab, where data about biomarkers from GeparQuinto, NSABP B-40, and BEATRICE are awaited. 
TABLE 4: Trials investigating dose-dense and dose-intensified neoadjuvant chemotherapy.

\begin{tabular}{|c|c|c|c|c|c|c|}
\hline Trial & Phase $(n)$ & Tumors & Treatment & Primary endpoint & Other outcomes & Ref. \\
\hline GeparDuo & III (904) & T2-3 N0-2, & $\begin{array}{l}4 \times \mathrm{DD} \text { ADoc, } \mathrm{q} 14+ \\
\mathrm{G}-\mathrm{CSF} \text { versus } 4 \times \mathrm{AC} \\
\quad \rightarrow 4 \times \text { Doc, } \mathrm{q} 21\end{array}$ & $\begin{array}{l}\text { pCR } 7 \text { versus } 14 \% \\
(P<.001) \\
\text { (closed early because of } \\
\text { pCR difference) }\end{array}$ & $\begin{array}{l}\text { BCT } 58 \text { versus } 63 \%(P=.05) ; \\
\text { cORR } 69 \text { versus } 79 \%(P<.001) ; \\
5 y \text {-EFS } 65 \text { versus } 66 \%(P=.66) ; \\
5 y \text {-OS } 81 \text { versus } 85 \%(P=.24) ; \\
\text { trend for an improved DFS and OS } \\
\text { for pts achieving a pCR } \\
\text { (recurrence/death, } 22 / 12 \% \text { versus } \\
29 / 17 \%, P=.37 / .32)\end{array}$ & $\begin{array}{c}{[20,59,} \\
60]\end{array}$ \\
\hline AGO-1 & III (668) & $\begin{aligned} \geq & 3 \mathrm{~cm} \text { or } \\
& \mathrm{cT} 4 \mathrm{~d}\end{aligned}$ & $\begin{array}{c}3 \times \mathrm{IDD} \mathrm{E} \rightarrow 3 \times \mathrm{Pac}, \\
\mathrm{q} 14 \text { versus } 4 \times \mathrm{E}+4 \times \\
\text { Pac, q21 } \\
+3 \times \mathrm{CMF} \text { after } \mathrm{S} \text { for } \\
\text { all }\end{array}$ & $\begin{array}{l}\text { pCR } 18 \text { versus } 10 \% \\
(P=.008)\end{array}$ & $\begin{array}{l}\text { BCS } 55 \text { versus } 50 \%(P=.26) ; \\
5 \text { y-DFS } 70 \text { versus } 59 \% \text { (HR } 0.71 \text {, } \\
P=.011) \text {; } \\
5 \text { y-OS } 83 \text { versus } 77 \% \text { (HR } 0.83 \text {, } \\
P=.041) \text {; no benefit for } \\
\text { inflammatory BC; } \\
\text { more nonhematologic toxicities, } \\
\text { anemia, and thrombocytopenia, but } \\
\text { similar neutropenia and infection } \\
\text { rates }\end{array}$ & {$[22]$} \\
\hline PREPARE & III (733) & $\begin{aligned} \geq 2 \mathrm{~cm} \text { or } \\
\\
\quad \mathrm{cT} 4 \mathrm{~d}\end{aligned}$ & $\begin{array}{c}3 \times \mathrm{IDD} \mathrm{E} \rightarrow 3 \times \mathrm{Pac} \\
+\mathrm{G}-\mathrm{CSF} \rightarrow \mathrm{CMF} \\
\mathrm{q} 14 \text { versus } \\
4 \times \mathrm{EC} \rightarrow 4 \times \mathrm{Pac} \\
\mathrm{q} 21 \\
\pm \mathrm{DA}\end{array}$ & $\begin{array}{l}3 \text { y-DFS } 79 \text { versus } 76 \% \\
(P=.37)\end{array}$ & $\begin{array}{l}3 \text { y-OS } 92 \text { versus } 88 \%(P=.24) ; \\
\text { pCR } 19 \text { versus } 13 \%(P=.043) ; \\
\text { pCR associated with better DFS } \\
(P=.001) ; \\
3 \text { y-DFS DA + versus }-: 74 \text { versus } \\
80 \%(P=.061)\end{array}$ & {$[23,24]$} \\
\hline SWOG 0012 & III (372) & IIB-IIIB & $\begin{array}{c}5 \times \mathrm{AC} \rightarrow 12 \times \mathrm{Pac} \\
\text { weekly versus } 15 \times \mathrm{A} \\
\text { weekly }+\mathrm{C} \text { daily p.o. } \\
+\mathrm{G} \text {-CSF }\end{array}$ & $\begin{array}{l}\text { pCR } 21 \text { versus } 24 \% \\
(P=.45)\end{array}$ & $\begin{array}{l}\text { No difference in DFS (HR } 1.03 \\
P=.87) \\
\text { no difference in OS (HR } 1.19 \\
P=.37 \text { ) }\end{array}$ & {$[61]$} \\
\hline MDACC & III (202) & IIA-IV & $\begin{array}{c}\text { FAC q21 versus } \\
\text { DI FAC + G-CSF q18 }\end{array}$ & pCR 9 versus $13 \%(P=.35)$ & $\begin{array}{l}\text { cORR } 77 \text { versus } 92 \%(P=.003) \\
5 y \text {-OS } 66 \text { versus } 67 \%(P=.61) \\
5 y \text {-DFS } 56 \text { versus } 67 \%(P=.12)\end{array}$ & {$[62]$} \\
\hline
\end{tabular}

DD: dose dense; IDD: intensified dose dense; DI: dose intensified; ADoc: doxorubicin, docetaxel; AC: doxorubicin, cyclophosphamide; Doc: docetaxel; Pac: paclitaxel; CMF: cyclophosphamide, methotrexat, 5-FU; DA: darbepoetin alpha; C: cyclophosphamide; FAC: 5FU, doxorubicin, cyclophosphamide; A: doxorubicin.

10.1. HER2-Positive Breast Cancer. The fastest dynamic in research can be observed in HER2-positive breast cancer.

Already, four drugs inhibiting the HER2 pathway are available (trastuzumab, lapatinib, pertuzumab, and trastuzumab emtansine). To overcome resistance to a HER2 blockade, several new substances, blocking HER2 itself or interacting molecules, are in clinical investigation. Ertumaxomab, for example, is a trifunctional, bispecific monoclonal antibody targeting HER2 and CD3. Neratinib, in contrast, is a tyrosine kinase inhibitor blocking HER1 and HER2 irreversibly.

Other approaches are tumor vaccines against HER2, a dual HER2 and insulin-like growth factor-1 receptor (IGF-1R) blockade, and inhibition of heat-shock protein 90 (HSP90).

10.2. Serial Biopsies and Window-of-Opportunity Trials. For a patient tailored therapy, biomarkers in tumor tissue or circulation, predicting treatment response or resistance, are needed. Due to the anatomic location of breast cancer, sequential biopsies during neoadjuvant treatment can be performed easily. Thereby, treatment-induced molecular changes can be monitored at an early time point to identify patients which respond. This principle has been shown for neoadjuvant endocrine therapy, where the extent of $\mathrm{Ki}-67$ expression after only 2 weeks of treatment was significantly correlated with survival [38].

In addition to the classical neoadjuvant trial, a new design could be of greater interest: the so-called windowof-opportunity trial. In this case, a short course of targeted therapy is given prior to surgical resection or prior to standard therapy. The endpoint of such trials is not necessarily response rate but changes of biological markers, for example, for apoptosis or proliferation. A hypothesis-generating trial like this was done with metformin in operable breast cancer, where metformin was given twice daily for a median of 18 days prior to surgery. Ki-67 staining in invasive tumor tissue decreased significantly (from 37 to $34 \%, P=.016$ ) and TUNEL staining increased (from 0.56 to $1.05, P=.004$ ) [39].

Window-of-opportunity studies can be initiated to prove the expected mechanism of action, to identify tumor resistance and sensitivity, or to establish a "biologically effective" dose of the investigated targeted agent.

10.3. Postneoadjuvant Trials. Another field for new study designs will be the postneoadjuvant situation. Patients not 
TABLE 5: The most important neoadjuvant phase-III trials in HER2-positive cancer.

\begin{tabular}{|c|c|c|c|c|c|c|}
\hline Trial & Phase $(n)$ & Tumors & Treatment & Primary endpoint & Other outcomes & Ref. \\
\hline Buzdar et al. & III $(42 / 164)$ & $\begin{array}{l}\text { HER2+, } \\
\text { II-IIIA }\end{array}$ & $\begin{array}{c}4 \times \mathrm{Pac} \rightarrow 4 \times \mathrm{FEC} \pm \\
\mathrm{H}(24 \times \text { weekly })\end{array}$ & $\begin{array}{l}\text { pCR } 67 \text { versus } 25 \% \\
(P=.02) ; \\
\text { (closed early because of } \\
\text { pCR difference) }\end{array}$ & $\begin{array}{l}\text { cORR } 96 \text { versus } 84 \%(P=\text { na); } \\
\text { no clinical cardiac failure; } \\
>10 \% \text { decrease in LVE } 7 \text { versus } 5 \\
\text { patients }\end{array}$ & [28] \\
\hline $\mathrm{NOAH}$ & $\begin{array}{c}\text { III }(99 \\
\text { Her } 2+/ 343)\end{array}$ & $\begin{array}{l}\text { T3 N1 or } \\
\text { T4 or N2-3 }\end{array}$ & $\begin{array}{l}3 \times \mathrm{APac} \rightarrow 4 \times \mathrm{Pac} \\
\quad \rightarrow 3 \times \mathrm{CMF} \pm \mathrm{H}\end{array}$ & $\begin{array}{l}3 \text { y-EFS } 71 \text { versus } 56 \% \\
(P=.013)\end{array}$ & $\begin{array}{l}\text { bpCR } 43 \text { versus } 22 \%(P=.0007) ; \\
\text { tpCR } 38 \text { versus } 19 \%(P=.001) \\
3 \text { y-OS } 87 \text { versus } 79 \%(P=.114) \text {; } \\
\text { despite concurrent administration } \\
\text { with doxorubicin CHF only } 2 \%\end{array}$ & {$[16]$} \\
\hline GeparQuattro & $\begin{array}{c}\text { III }(445 \\
\text { HER2+/1509) }\end{array}$ & $\begin{array}{l}\text { T1c-4d } \\
\text { N0-3 (N0 } \\
\text { only if } \\
\text { HR-) }\end{array}$ & $\begin{array}{c}4 \times \mathrm{EC} \rightarrow 4 \times \mathrm{Doc} \\
+\mathrm{H}(\mathrm{HER} 2+) \pm \mathrm{X} \\
(\text { combination or } \\
\text { sequence })\end{array}$ & $\begin{array}{l}\text { tpCR } 32 \text { versus } 16 \% \\
(P<.001)\end{array}$ & $\begin{array}{l}\text { BCT } 63 \text { versus } 65 \% \text { (ns); } \\
\text { pCR Doc versus Doc + X versus } \\
\text { Doc } \rightarrow \text { X } \\
22 \text { versus } 20 \text { versus } 22 \% \text { (ns); } \\
\text { BCT } 70 \text { versus } 68 \text { versus } 65 \% \text { (ns) }\end{array}$ & {$[12,30]$} \\
\hline TECHNO & II (217) & $\begin{array}{l}\mathrm{HER} 2+ \\
\geq 2 \mathrm{~cm} \text { or } \\
\quad \text { cT } 4 \mathrm{~d}\end{array}$ & $\begin{array}{c}4 \times \mathrm{EC} \rightarrow 4 \times \mathrm{Pac} \\
+\mathrm{H}\end{array}$ & pCR 39\% & $\begin{array}{l}\text { BCT } 65 \% \text {; CHF } 3.7 \% \\
3 \text { y-DFS 78\% } \\
3 \text { y-DFS pCR versus non: } 96 \text { versus } \\
86 \%(P=.003)\end{array}$ & {$[29]$} \\
\hline $\begin{array}{l}\text { GeparQuinto } \\
\text { (Her2 positive) }\end{array}$ & III (620) & $\begin{array}{l}\text { cT3/4; cT2 } \\
\text { if } \mathrm{HR}-\text { or } \\
\text { cN+; cT1 if } \\
\text { HR- or } \\
\text { SLN+ }\end{array}$ & $\begin{array}{l}4 \times \mathrm{EC} \rightarrow 4 \times \mathrm{Doc} \\
\quad+\mathrm{H} \text { versus } \mathrm{L}\end{array}$ & $\begin{array}{l}\text { pCR } 30 \text { versus } 23 \% \\
(P=.04)\end{array}$ & $\begin{array}{l}\text { cORR } 90 \% \text { both }(\mathrm{ns}) \\
\text { diarrhea } \geq \text { gr } 3: 3 \text { versus } 12 \% \\
(P<.0001) \\
\text { CHF } 1 \text { versus } 7 \text { (ns) }\end{array}$ & {$[34]$} \\
\hline CHER-LOB & II (121) & $\begin{array}{l}\text { HER2+, } \\
\text { II-IIIA }\end{array}$ & $\begin{array}{c}12 \times \mathrm{Pac} \rightarrow 4 \times \mathrm{FEC} \\
+\mathrm{H} \text { versus } \mathrm{L} \text { versus } \mathrm{L} \\
+\mathrm{H}\end{array}$ & $\begin{array}{l}\text { pCR } 25 \text { versus } 26 \text { versus } \\
47 \%(\mathrm{~L} / \mathrm{H} \text { versus } \mathrm{L}+\mathrm{H} \text { : } \\
\left.P_{\text {exploratory }}=.019\right)\end{array}$ & $\begin{array}{l}\text { BCT } 67 \text { versus } 58 \text { versus } 70 \% \text {; } \\
\text { diarrhea } \geq \text { gr } 3: 3 \text { versus } 36 \text { versus } \\
35 \%\end{array}$ & {$[32]$} \\
\hline NEO-ALTTO & III (455) & $\begin{array}{l}\mathrm{HER} 2+ \\
\geq 2 \mathrm{~cm}\end{array}$ & $\begin{array}{l}6 \times \mathrm{H}(\mathrm{w}) \text { versus } \mathrm{L} \\
\text { versus } \mathrm{L}+\mathrm{H}(\mathrm{w}) \rightarrow \\
\text { combination with } 12 \\
\times \mathrm{Pac}(\mathrm{w}) \rightarrow \mathrm{S} \rightarrow \\
\text { FEC }+ \text { same schedule } \\
\quad \text { for } 1 \mathrm{y}\end{array}$ & $\begin{array}{l}\text { pCR } 30 \text { versus } 25 \text { versus } \\
51 \%(H \text { versus } \mathrm{L}+\mathrm{H}: \\
P=.0001 ; \mathrm{H} \text { versus } \mathrm{L}: \\
P=.34)\end{array}$ & $\begin{array}{l}\text { cORR after } 6 \text { weeks } 30 \text { versus } 53 \\
\text { versus } 67 \% \text { (both } P<.0001) ; \\
\text { cORR at surgery } 71 \text { versus } 74 \\
(P=.49) \text { versus } 80 \%(P=.049) \\
\text { diarrhea } \geq \text { gr } 3: 2 \text { versus } 23 \text { versus } \\
21 \%\end{array}$ & [63] \\
\hline NSABP B-41 & III (522) & $\begin{array}{l}\mathrm{HER} 2+ \\
\geq 2 \mathrm{~cm}\end{array}$ & $\begin{array}{l}4 \times \mathrm{AC} \rightarrow 4 \times \text { Doc }+ \\
\mathrm{H}(\mathrm{w}) \text { versus } \mathrm{L} \text { versus } \\
\mathrm{L}+\mathrm{H}(\mathrm{w})(+\mathrm{H} \text { for } 1 \mathrm{y} \\
\quad \text { adjuvant for all })\end{array}$ & $\begin{array}{l}\text { pCR } 53 \text { versus } 53 \text { versus } \\
62 \% \text { ( } \mathrm{H} \text { versus } \mathrm{L}+\mathrm{H}: \\
P=.075 ; \mathrm{H} \text { versus } \mathrm{L}: \\
P=.9)\end{array}$ & $\begin{array}{l}\text { diarrhea } \geq \text { gr } 3: 2 \text { versus } 20 \text { versus } \\
27 \%(P<.001) \\
C H F \geq \text { gr } 3: 4 \text { versus } 4 \text { versus } 2 \% \\
(P=0.49)\end{array}$ & {$[33]$} \\
\hline NeoSphere & II (417) & $\begin{array}{l}\text { HER } 2+ \\
\geq 2 \mathrm{~cm} \text { or } \\
\quad \text { cT } 4 \mathrm{~d}\end{array}$ & $\begin{array}{c}\text { (A) } 4 \times \text { Doc }+\mathrm{H} \\
\text { versus } \\
\text { (B) } 4 \times \text { Doc }+\mathrm{H}+\mathrm{P} \\
\text { versus } \\
\text { (C) } \mathrm{H}+\mathrm{P} \text { versus } \\
\text { (D) } 4 \times \text { Doc }+\mathrm{P}\end{array}$ & $\begin{array}{l}\text { pCR } 29 \text { versus } 46 \text { versus } \\
17 \text { versus } 24 \% \\
\text { (B versus A: } P=.0141 \\
\text { C versus A: } P=.019 \\
\text { B versus D: } P=.003 \text { ) }\end{array}$ & $\begin{array}{l}\text { cORR } 81 \text { versus } 88 \text { versus } 66 \text { versus } \\
74 \%\end{array}$ & {$[35]$} \\
\hline TRYPHAENA & II (225) & $\begin{array}{l}\text { HER2+, } \\
\text { II-III }\end{array}$ & $\begin{array}{c}3 \times \mathrm{FEC}+\mathrm{H}+\mathrm{P} \rightarrow 3 \\
\times \mathrm{Doc}+\mathrm{H}+\mathrm{P} \text { versus } \\
3 \times \mathrm{FEC} \rightarrow 3 \times \text { Doc } \\
+\mathrm{H}+\mathrm{P} \text { versus } 6 \times \\
\text { Doc }+ \text { Carbo }+\mathrm{H}+\mathrm{P}\end{array}$ & $\begin{array}{l}\text { Cardiac safety: } \\
\text { symptomatic LVSD } 0 \\
\text { versus } 2.7 \text { versus } 0 \%\end{array}$ & $\begin{array}{l}\text { pCR } 62 \text { versus } 57 \text { versus } 66 \% \text {; } \\
\text { cORR } 92 \text { versus } 95 \text { versus } 90 \%\end{array}$ & {$[36]$} \\
\hline
\end{tabular}

Pac: paclitaxel; FEC: 5FU, epirubicin, cyclophosphamide; H: trastuzumab; APac: doxorubicin, paclitaxel; X: capecitabine; L: lapatinib; w: weekly; Doc: docetaxel; Carbo: carboplatin; na: not available; bpCR: pathological complete response in breast tissue; tpCR: total pathological complete response (inbreast and axillary nodes); LVSD: left ventricular end-systolic dimension.

achieving a pCR will be randomized postoperatively to a new therapy or to the established standard treatment, if available. Such a trial design is planned to compare trastuzumab emtansine (T-DM1) with classical trastuzumab as a treatment for patients with residual invasive disease following standard neoadjuvant therapy in HER2-positive cancer. The goal of post-neoadjuvant trials is to improve the poor prognosis of nonluminal breast cancer patients in case of residual disease.

10.4. New Registration Pathway. In May 2012, the FDA announced to reconsider the actual process of marketing approval for drugs in the neoadjuvant setting. Historically, 
new drugs for breast cancer had to be approved in the metastatic setting upfront, followed by adjuvant trials requiring many years of followup. As a result, the time from initiation of a phase III trial in the metastatic setting to approval for adjuvant use is often well more than a decade. Therefore, the FDA initiated a discussion to use pCR as an endpoint in high risk breast cancer to support approval under the accelerated approval regulations. To this end, the Collaborative Trials in Neoadjuvant Breast Cancer (CTNeoBC) working group, harboring investigators of different international study groups, has initiated a large meta-analysis to clarify the relationship between pCR and DFS/OS using primary source data from more than 12,000 patients enrolled in published randomized neoadjuvant trials. This potential new registration pathway would accelerate availability of new drugs and therefore help addressing an unmet need in these high risk populations.

\section{Abbreviations}

2MT: Mitoxantrone, metotrexat, tamoxifen

A: Doxorubicin

AC: Doxorubicin, cyclophosphamide

ADoc: Doxorubicin, docetaxel

APac: Doxorubicin, paclitaxel

Bev: Bevacizumab

BCT: Breast conserving therapy

bpCR: Pathological complete response in breast tissue

C: Cyclophosphamide

Carbo: Carboplatin

cCR: Clinical complete response

CHF: Chronic heart failure

CMF: Cyclophosphamide, metotrexat, 5-FU

cORR: Clinical overall response rate

cPR: Clinical partial response

CVAP: Cyclophosphamide, vincristine, doxorubicin, prednisone

DA: Darbepoetin alpha

DD: Dose dense

DI: Dose intensified

DFS: Disease-free survival

Doc: Docetaxel

EC: Epirubicin, cyclophosphamide

ETV: Mitomycin, thiotepa, vindesin

EVM: Epirubicin, vincristine, metotrexat

FEC: 5-FU, epirubicin, cyclophosphamide

FAC: 5FU, doxorubicin, cyclophosphamide

$\mathrm{H}$ : Trastuzumab

IDD: Intensified dose-dense

L: $\quad$ Lapatinib

LRR: Local recurrence rate

LVSD: Left ventricular end-systolic dimension

MO: Months

na: Not available

NA: Neoadjuvant

NX: Vinorelbine, capecitabine

OS: Overall survival

Pac: Paclitaxel

pCR: Pathologic complete response
Rad001: Everolimus

RCB: Residual cancer burden

RFS: Recurrence-free survival

RT: Radiotherapy

S: $\quad$ Surgery

TAC: Docetaxel, doxorubicin, cyclophosphamide

tpCR: Total pathological complete response (inbreast and axillary nodes)

$\mathrm{N}$ : $\quad$ Vinorelbine

X: $\quad$ Capecitabine.

\section{Authors' Contribution}

Simon P. Gampenrieder contributed to the conception and design, collection and assembly of data, and writing of the paper; Gabriel Rinnerthaler and Richard Greil to the critical revising of the paper; and all authors to data analysis and interpretation and the final approval of the paper.

\section{Acknowledgments}

Richard Greil had the role of an advisor or consultant for Roche, Celgene, Teva, Takeda, BMS, and Novartis and also an honorarium speaker for Roche. Simon P. Gampenrieder received travel grants from Roche, Amgen, and GlaxoSmithKline and Gabriel Rinnerthaler from Roche, Amgen, Merck, and Pfizer; Richard Greil also received research funding from Roche, Novartis, Amgen, Takeda, and Teva and Simon P. Gampenrieder and Gabriel Rinnerthaler from Roche.

\section{References}

[1] R. Rastogi, S. J. Anderson, and H. D. Bear, "Preoperative chemotherapy: updates of national surgical adjuvant breast and bowel project protocols B-18 and B-27," Journal of Clinical Oncology, vol. 26, no. 16, p. 2793, 2008.

[2] J. A. Van der Hage, C. J. H. Van de Velde, J.-P. Julien, M. Tubiana-Hulin, C. Vandervelden, and L. Duchateau, "Preoperative chemotherapy in primary operable breast cancer: results from the European Organization for research and Treatment of Cancer Trial 10902," Journal of Clinical Oncology, vol. 19, no. 22, pp. 4224-4237, 2001.

[3] D. Mauri, N. Pavlidis, and J. P. A. Ioannidis, "Neoadjuvant versus adjuvant systemic treatment in breast cancer: a metaanalysis," Journal of the National Cancer Institute, vol. 97, no. 3, pp. 188-194, 2005.

[4] R. Greil, "The still long and winding road to neoadjuvant sytemic therapy as the standard of care in breast cancer," Breast Care, vol. 1, no. 6, pp. 352-357, 2006.

[5] A. W. Hutcheon, S. D. Heys, T. K. Sarkar et al., "Docetaxel primary chemotherapy in breast cancer: a five year update of the Aberdeen trial," Breast Cancer Research and Treatment, vol. 82, supplement 1, p. S6, 2003.

[6] F. Cuppone, E. Bria, P. Carlini et al., "Taxanes as primary chemotherapy for early breast cancer: meta-analysis of randomized trials," Cancer, vol. 113, no. 2, pp. 238-246, 2008.

[7] I. E. Smith, R. P. A'Hern, G. A. Coombes et al., "A novel continuous infusional 5-fluorouracil-based chemotherapy regimen 
compared with conventional chemotherapy in the neo-adjuvant treatment of early breast cancer: 5 year results of the TOPIC trial," Annals of Oncology, vol. 15, no. 5, pp. 751-758, 2004.

[8] S. Chua, I. E. Smith, R. P. A'Hern et al., "Neoadjuvant vinorelbine/epirubicin (VE) versus standard adriamycin/ cyclophosphamide (AC) in operable breast cancer: analysis of response and tolerability in a randomised phase III trial (TOPIC 2)," Annals of Oncology, vol. 16, no. 9, pp. 1435-1441, 2005.

[9] H. M. Earl, A. Vallier, L. Hiller et al., "Neo-tAnGo: A neoadjuvant randomized phase III trial of epirubicin/cyclophosphamide and paclitaxel \pm gemcitabine in the treatment of women with high-risk early breast cancer (EBC): first report of the primary endpoint, pathological complete response (pCR)," Journal of Clinical Oncology, vol. 27, supplement 15, abstract 522, 2009.

[10] H. D. Bear, G. Tang, P. Rastogi et al., "Bevacizumab added to neoadjuvant chemotherapy for breast cancer," The New England Journal of Medicine, vol. 366, no. 4, pp. 310-320, 2012.

[11] G. G. Steger, R. Greil, R. Jakesz et al., "Pathologic complete response (pCR) in patient subgroups: an analysis of ABCSG24, a phase III, randomized study of anthracycline- and taxanebased neoadjuvant therapy with or without capecitabine in early breast cancer (EBC)," Journal of Clinical Oncology, vol. 28, supplement 15, abstract 530, 2010.

[12] G. Von Minckwitz, M. Rezai, S. Loibl et al., "Capecitabine in addition to anthracycline- and taxane-based neoadjuvant treatment in patients with primary breast cancer: phase III GeparQuattro Study," Journal of Clinical Oncology, vol. 28, no. 12, pp. 2015-2023, 2010.

[13] J. S. Mieog, J. A. van der Hage, and C. J. van de Velde, "Preoperative chemotherapy for women with operable breast cancer," Cochrane Database of Systematic Reviews, no. 2, Article ID CD005002, 2007.

[14] C. Mazouni, F. Peintinger, S. Wan-Kau et al., "Residual ductal carcinoma in situ in patients with complete eradication of invasive breast cancer after neoadjuvant chemotherapy does not adversely affect patient outcome," Journal of Clinical Oncology, vol. 25, no. 19, pp. 2650-2655, 2007.

[15] G. von Minckwitz, M. Untch, J. U. Blohmer et al., "Definition and impact of pathologic complete response on prognosis after neoadjuvant chemotherapy in various intrinsic breast cancer subtypes," Journal of Clinical Oncology, vol. 30, no. 15, pp. 17961804, 2012.

[16] L. Gianni, W. Eiermann, V. Semiglazov et al., "Neoadjuvant chemotherapy with trastuzumab followed by adjuvant trastuzumab versus neoadjuvant chemotherapy alone, in patients with HER2-positive locally advanced breast cancer (the NOAH trial): a randomised controlled superiority trial with a parallel HER2-negative cohort," The Lancet, vol. 375, no. 9712, pp. 377$384,2010$.

[17] B. Mlineritsch, C. Tausch, C. Singer et al., "Exemestane as primary systemic treatment for hormone receptor positive postmenopausal breast cancer patients: a phase II trial of the Austrian Breast and Colorectal Cancer Study Group (ABCSG17)," Breast Cancer Research and Treatment, vol. 112, no. 1, pp. 203-213, 2008.

[18] G. von Minckwitz, J. U. Blohmer, S. Costa et al., "Neoadjuvant chemotherapy adapted by interim response improves overall survival of primary breast cancer patients-results of the gepartrio trial," Cancer Research, vol. 71, no. 24, abstract S3-2, 2011.
[19] J. Huober, C. Hanusch, P. A. Fasching et al., "Neoadjuvant chemotherapy of paclitaxel with or without Rad001: results of the non-responder part of the GEPARQUINTO Study," Cancer Research, vol. 71, no. 24, absrtact 3-6, 2011.

[20] M. Kaufmann, W. Eiermann, M. Schuette et al., "Long-term results from the neoadjuvant GeparDuo trial: A randomized, multicenter, Open Phase III Study comparing a dose-intensified 8 -week schedule of doxorubicin hydrochloride and docetaxel (ADoc) with a sequential 24-week schedule of doxorubicin hydrochloride/cyclophosphamide followed by docetaxel (ACDoc) regimen as preoperative therapy (NACT) in patients (pts) with operable breast cancer," Journal of Clinical Oncology, vol. 28, supplement 15, abstract 537, 2010.

[21] G. K. Ellis, W. E. Barlow, J. R. Gralow et al., "Phase III comparison of standard doxorubicin and cyclophosphamide versus weekly doxorubicin and daily oral cyclophosphamide plus granulocyte colony-stimulating factor as neoadjuvant therapy for inflammatory and locally advanced breast cancer: SWOG 0012," Journal of Clinical Oncology, vol. 29, no. 8, pp. 1014-1021, 2011.

[22] M. Untch, V. Möbus, W. Kuhn et al., "Intensive dose-dense compared with conventionally scheduled preoperative chemotherapy for high-risk primary breast cancer," Journal of Clinical Oncology, vol. 27, no. 18, pp. 2938-2945, 2009.

[23] M. Untch, P. A. Fasching, G. E. Konecny et al., "PREPARE trial: a randomized phase III trial comparing preoperative, dose-dense, dose-intensified chemotherapy with epirubicin, paclitaxel and CMF versus a standard-dosed epirubicin/cyclophosphamide followed by paclitaxel \pm darbepoetin alfa in primary breast cancer-results at the time of surgery," Annals of Oncology, vol. 22, no. 9, pp. 1988-1998, 2011.

[24] M. Untch, G. von Minckwitz, G. E. Konecny et al., "PREPARE trial: a randomized phas III trial comparing preoperative, dose-dense, dose-intensified chemotherapy with epirubicin, paclitaxel, and CMF versus a standard-dosed epirubicincyclophosphamide followed by paclitaxel with or without darbepoetin alfa in primary breast cancer-outcome on prognosis," Annals of Oncology, vol. 22, no. 9, pp. 1999-2006, 2011.

[25] G. Von Minckwitz, M. Untch, E. Nüesch et al., "Impact of treatment characteristics on response of different breast cancer phenotypes: pooled analysis of the German neo-adjuvant chemotherapy trials," Breast Cancer Research and Treatment, vol. 125, no. 1, pp. 145-156, 2011.

[26] R. E. Smith, J. Bryant, A. DeCillis, and S. Anderson, "Acute myeloid leukemia and myelodysplastic syndrome after doxorubicin-cyclophosphamide adjuvant therapy for operable breast cancer: The National Surgical Adjuvant Breast and Bowel Project experience," Journal of Clinical Oncology, vol. 21, no. 7, pp. 1195-1204, 2003.

[27] J. E. Karp, A. Blackford, K. Visvanathan et al., "Myelodysplatic syndrome and/or acute myelogenous leukemia (MDS and/or AML) after a breast cancer diagnosis: the National Comprehensive Cancer Network (NCCN) experience," in Proceedings of the San Antonio Breast Cancer Symposium, vol. 2012, abstract 3-5, 2012.

[28] A. U. Buzdar, N. K. Ibrahim, D. Francis et al., "Significantly higher pathologic complete remission rate after neoadjuvant therapy with trastuzumab, paclitaxel, and epirubicin chemotherapy: results of a randomized trial in human epidermal growth factor receptor 2-positive operable breast cancer," Journal of Clinical Oncology, vol. 23, no. 16, pp. 3676-3685, 2005.

[29] M. Untch, P. A. Fasching, G. E. Konecny et al., "Pathologic complete response after neoadjuvant chemotherapy plus 
trastuzumab predicts favorable survival in human epidermal growth factor receptor 2-overexpressing breast cancer: results from the TECHNO Trial of the AGO and GBG Study Groups," Journal of Clinical Oncology, vol. 29, no. 25, pp. 3351-3357, 2011.

[30] M. Untch, M. Rezai, S. Loibl et al., "Neoadjuvant treatment with trastuzumab in HER2-positive breast cancer: results from the GeparQuattro Study," Journal of Clinical Oncology, vol. 28, no. 12, pp. 2024-2031, 2010.

[31] J. Baselga, I. Bradbury, and H. Eidtmann, "Lapatinib with trastuzumab for HER2-positive early breast cancer (NeoALTTO): a randomised, open-label, multicentre, phase 3 trial "” The Lancet, vol. 379, no. 9816, p. 616, 2012.

[32] V. Guarneri,, A. Frassoldati, A. Bottini et al., "Preoperative chemotherapy plus trastuzumab, lapatinib, or both in human epidermal growth factor receptor 2-positive operable breast cancer: results of the randomized phase II CHER-LOB study," Journal of Clinical Oncology, vol. 30, no. 16, pp. 1989-1995, 2012.

[33] A. Robidoux, G. Tang, P. Rastogi et al., "Evaluation of lapatinib as a component of neoadjuvant therapy for HER2+ operable breast cancer: NSABP protocol B-41," Journal of Clinical Oncology, vol. 30, abstract LBA506, 2012.

[34] M. Untch, S. Loibl, J. Bischoff et al., "Lapatinib versus trastuzumab in combination with neoadjuvant anthracyclinetaxane-based chemotherapy (GeparQuinto, GBG 44): a randomised phase 3 trial," The Lancet Oncology, vol. 13, no. 2, pp. 135-144, 2012.

[35] L. Gianni, T. Pienkowski, Y.-H. Im et al., "Efficacy and safety of neoadjuvant pertuzumab and trastuzumab in women with locally advanced, inflammatory, or early HER2-positive breast cancer (NeoSphere): a randomised multicentre, open-label, phase 2 trial," The Lancet Oncology, vol. 13, no. 1, pp. 25-32, 2012.

[36] A. Schneeweiss, S. Chia, T. Hickish et al., "Neoadjuvant pertuzumab and trastuzumab concurrent or sequential with an anthracycline-containing or concurrent with an anthracyclineFree standard regimen: A Randomized Phase II Study (TRYPHAENA)," Cancer Research, vol. 71, supplement 3, abstract S5-6, no. 24, 2011.

[37] G. Von Minckwitz, H. Eidtmann, M. Rezai et al., "Neoadjuvant chemotherapy and bevacizumab for HER2-negative breast cancer," The New England Journal of Medicine, vol. 366, no. 4, pp. 299-309, 2012.

[38] M. Dowsett, I. E. Smith, S. R. Ebbs et al., "Prognostic value of Ki67 expression after short-term presurgical endocrine therapy for primary breast cancer," Journal of the National Cancer Institute, vol. 99, no. 2, pp. 167-170, 2007.

[39] S. Niraula, R. J. Dowling, M. Ennis et al., "Metformin in early breast cancer: a prospective window of opportunity neoadjuvant study," Breast Cancer Research and Treatment, vol. 135, no. 3, pp. 821-830, 2012.

[40] L. Mauriac, G. MacGrogan, A. Avril et al., "Neoadjuvant chemotherapy for operable breast carcinoma larger than $3 \mathrm{~cm}$ : a unicentre randomized trial with a 124-month median followup," Annals of Oncology, vol. 10, no. 1, pp. 47-52, 1999.

[41] L. Mauriac, M. Durand, A. Avril, and J.-M. Dilhuydy, "Effects of primary chemotherapy in conservative treatment of breast cancer patients with operable tumors larger than $3 \mathrm{~cm}$. results of a randomized trial in a single centre," Annals of Oncology, vol. 2, no. 5, pp. 347-354, 1991.

[42] S. M. Scholl, A. Fourquet, B. Asselain et al., "Neoadjuvant versus adjuvant chemotherapy in premenopausal patients with tumours considered too large for breast conserving surgery: preliminary results of a randomised trial: S6," European Journal of Cancer A, vol. 30, no. 5, pp. 645-652, 1994.

[43] P. Broët, S. M. Scholl, A. De la Rochefordière et al., "Short and long-term effects on survival in breast cancer patients treated by primary chemotherapy: an updated analysis of a randomized trial," Breast Cancer Research and Treatment, vol. 58, no. 2, pp. 151-156, 1999.

[44] A. Makris, T. J. Powles, S. E. Ashley et al., "A reduction in the requirements for mastectomy in a randomized trial of neoadjuvant chemoendocrine therapy in primary breast cancer," Annals of Oncology, vol. 9, no. 11, pp. 1179-1184, 1998.

[45] T. J. Powles, T. F. Hickish, A. Makris et al., "Randomized trial of chemoendocrine therapy started before or after surgery for treatment of primary breast cancer," Journal of Clinical Oncology, vol. 13, no. 3, pp. 547-552, 1995.

[46] B. Fisher, J. Bryant, N. Wolmark et al., "Effect of preoperative chemotherapy on the outcome of women with operable breast cancer," Journal of Clinical Oncology, vol. 16, no. 8, pp. 26722685, 1998.

[47] N. Wolmark, J. Wang, E. Mamounas, J. Bryant, and B. Fisher, "Preoperative chemotherapy in patients with operable breast cancer: nine-year results from National Surgical Adjuvant Breast and Bowel Project B-18," Journal of the National Cancer Institute. Monographs, no. 30, pp. 96-102, 2001.

[48] S. Taucher, G. G. Steger, R. Jakesz et al., "The potential risk of neoadjuvant chemotherapy in breast cancer patients-results from a prospective randomized trial of the Austrian Breast and Colorectal Cancer Study Group (ABCSG-07)," Breast Cancer Research and Treatment, vol. 112, no. 2, pp. 309-316, 2008.

[49] S. D. Heys, A. W. Hutcheon, T. K. Sarkar et al., "Neoadjuvant docetaxel in breast cancer: 3-year survival results from the Aberdeen trial," Clinical Breast Cancer, vol. 3, no. 2, pp. S69S74, 2002.

[50] I. C. Smith, S. D. Heys, and A. W. Hutcheon, "Neoadjuvant chemotherapy in breast cancer: significantly enhanced response with docetaxel," Journal of Clinical Oncology, vol. 20, no. 6, pp. 1456-1466, 2002.

[51] H. D. Bear, S. Anderson, A. Brown et al., "The effect on tumor response of adding sequential preoperative docetaxel to preoperative doxorubicin and cyclophosphamide: preliminary results from National Surgical Adjuvant Breast and Bowel Project Protocol B-27," Journal of Clinical Oncology, vol. 21, no. 22, pp. 4165-4174, 2003.

[52] H. D. Bear, S. Anderson, and R. E. Smith, "Sequential preoperative or postoperative docetaxel added to preoperative doxorubicin plus cyclophosphamide for operable breast cancer: National Surgical Adjuvant Breast and Bowel Project Protocol B-27," Journal of Clinical Oncology, vol. 24, no. 13, pp. 2019-2027, 2006.

[53] T. R. J. Evans, A. Yellowlees, E. Foster et al., "Phase III randomized trial of doxorubicin and docetaxel versus doxorubicin and cyclophosphamide as primary medical therapy in women with breast cancer: an Anglo-Celtic Cooperative Oncology Group Study," Journal of Clinical Oncology, vol. 23, no. 13, pp. 29882995, 2005.

[54] V. Diéras, P. Fumoleau, G. Romieu et al., "Randomized Parallel Study of doxorubicin plus paclitaxel and doxorubicin plus cyclophosphamide as neoadjuvant treatment of patients with breast cancer," Journal of Clinical Oncology, vol. 22, no. 24, pp. 4958-4965, 2004.

[55] G. von Minckwitz, J.-U. Blohmer, G. Raab et al., "In vivo chemosensitivity-adapted preoperative chemotherapy in patients 
with early-stage breast cancer: The GEPARTRIO pilot study," Annals of Oncology, vol. 16, no. 1, pp. 56-63, 2005.

[56] G. Von Minckwitz, S. Kümmel, P. Vogel et al., "Intensified neoadjuvant chemotherapy in early-responding breast cancer: phase III randomized GeparTrio study," Journal of the National Cancer Institute, vol. 100, no. 8, pp. 552-562, 2008.

[57] G. Von Minckwitz, S. Kümmel, P. Vogel et al., "Neoadjuvant vinorelbine-capecitabine versus docetaxel-doxorubicincyclophosphamide in early nonresponsive breast cancer: phase III randomized gepartrio trial," Journal of the National Cancer Institute, vol. 100, no. 8, pp. 542-551, 2008.

[58] G. Von Minckwitz, B. M. Müller, S. Loibl et al., "Cytoplasmic poly(adenosine diphosphate-ribose) polymerase expression is predictive and prognostic in patients with breast cancer treated with neoadjuvant chemotherapy," Journal of Clinical Oncology, vol. 29, no. 16, pp. 2150-2157, 2011.

[59] G. Von Minckwitz, G. Raab, A. Caputo et al., "Doxorubicin with cyclophosphamide followed by docetaxel every 21 days compared with doxorubicin and docetaxel every 14 days as preoperative treatment in operable breast cancer: the GEPARDUO study of the German Breast Group," Journal of Clinical Oncology, vol. 23, no. 12, pp. 2676-2685, 2005.

[60] D. Mohamed, G. Raab, M. Schuette et al., "Dose-dense versus sequential adriamcycin/docetaxel combination as preoperative chemotherapy (pCHT) in operable breast cancer (T2-3, N02,M0) - primary endpoint analysis of the GEPARDUO-Study," Journal of Clinical Oncology, vol. 21, abstract 168, 2002.

[61] G. K. Ellis, W. E. Barlow, J. R. Gralow et al., "Phase III comparison of standard doxorubicin and cyclophosphamide versus weekly doxorubicin and daily oral cyclophosphamide plus granulocyte colony-stimulating factor as neoadjuvant therapy for inflammatory and locally advanced breast cancer: SWOG 0012," Journal of Clinical Oncology, vol. 29, no. 8, pp. 1014-1021, 2011.

[62] B. K. Arun, K. Dhinghra, V. Valero et al., "Phase III randomized trial of dose intensive neoadjuvant chemotherapy with or without G-CSF in locally advanced breast cancer: long-term results," Oncologist, vol. 16, no. 11, pp. 1527-1534, 2011.

[63] J. Baselga, I. Bradbury, and H. Eidtmann, "First results of the NeoALTTO trial (BIG 01-06/EGF 106903): a phase III, randomized, open label, Neoadjuvant Study of lapatinib, trastuzumab, and their combination plus paclitaxel in Women with HER2positive primary breast cancer ", Cancer Research, vol. 70, supplement 24, abstract S3-3, pp. 157-158, 2010. 


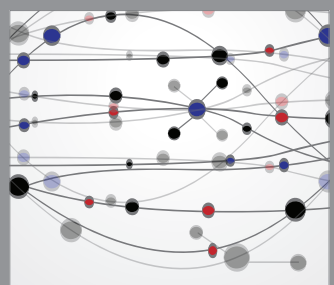

The Scientific World Journal
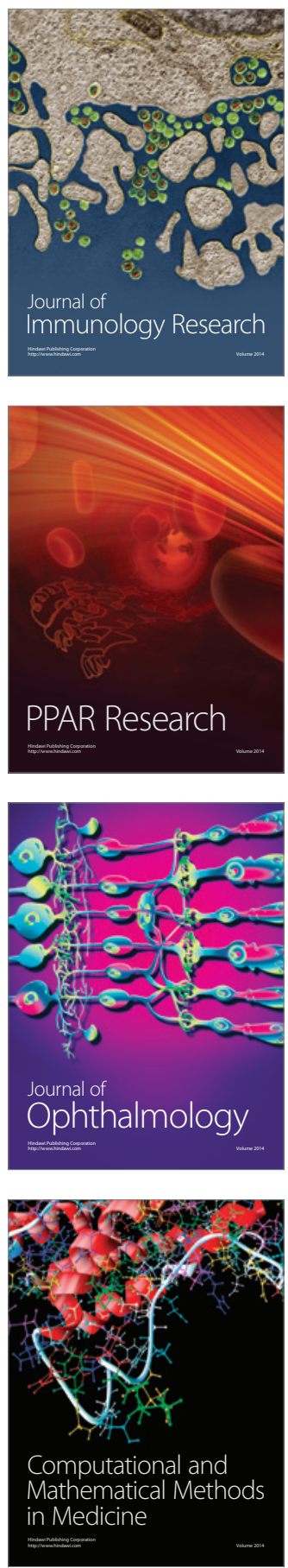

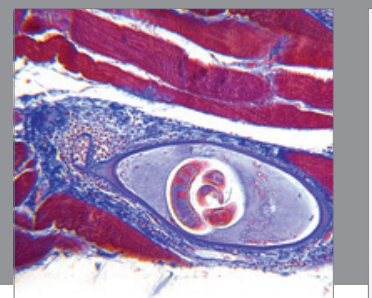

Gastroenterology

Research and Practice
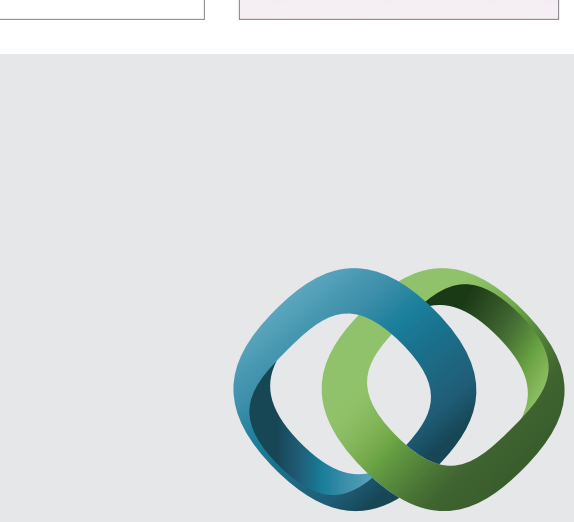

\section{Hindawi}

Submit your manuscripts at

http://www.hindawi.com
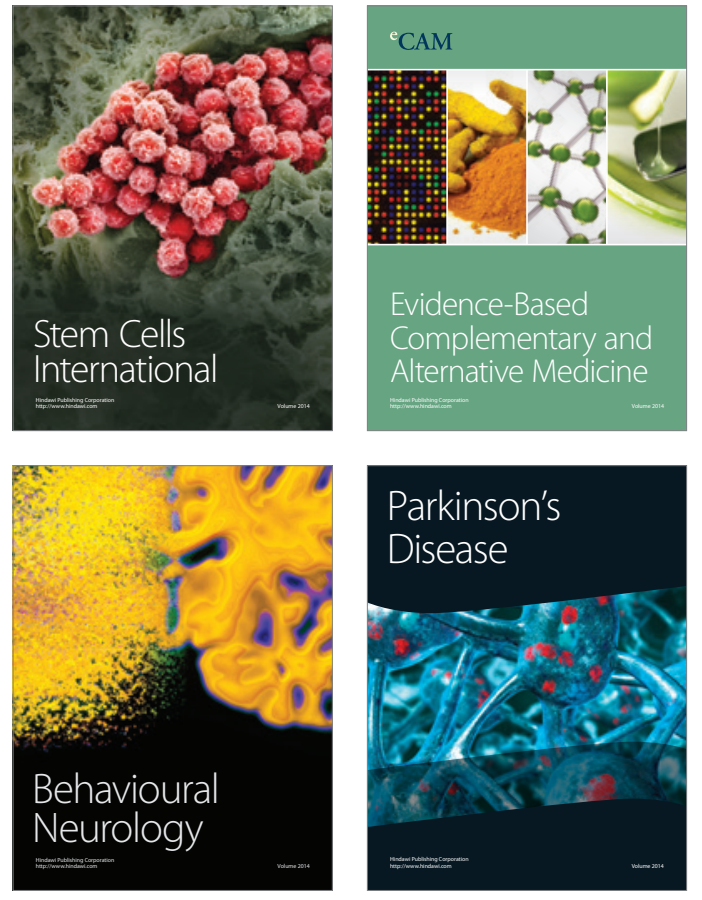
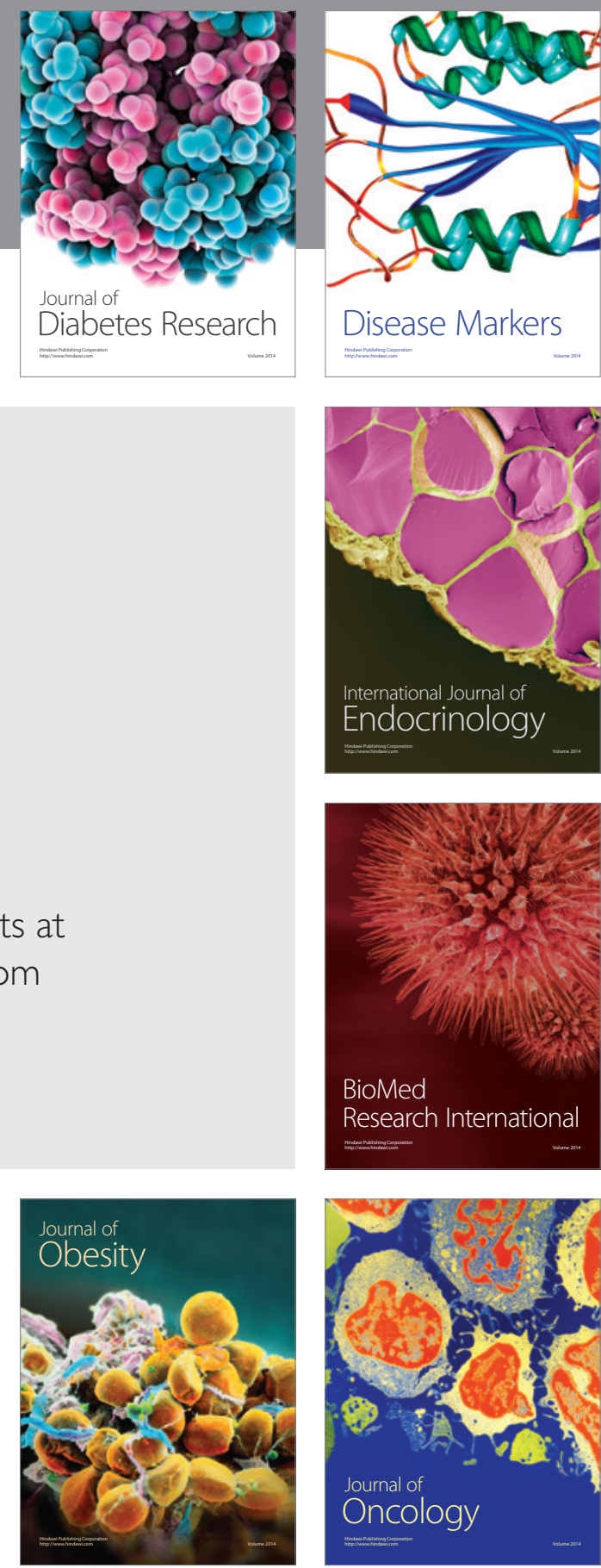

Disease Markers
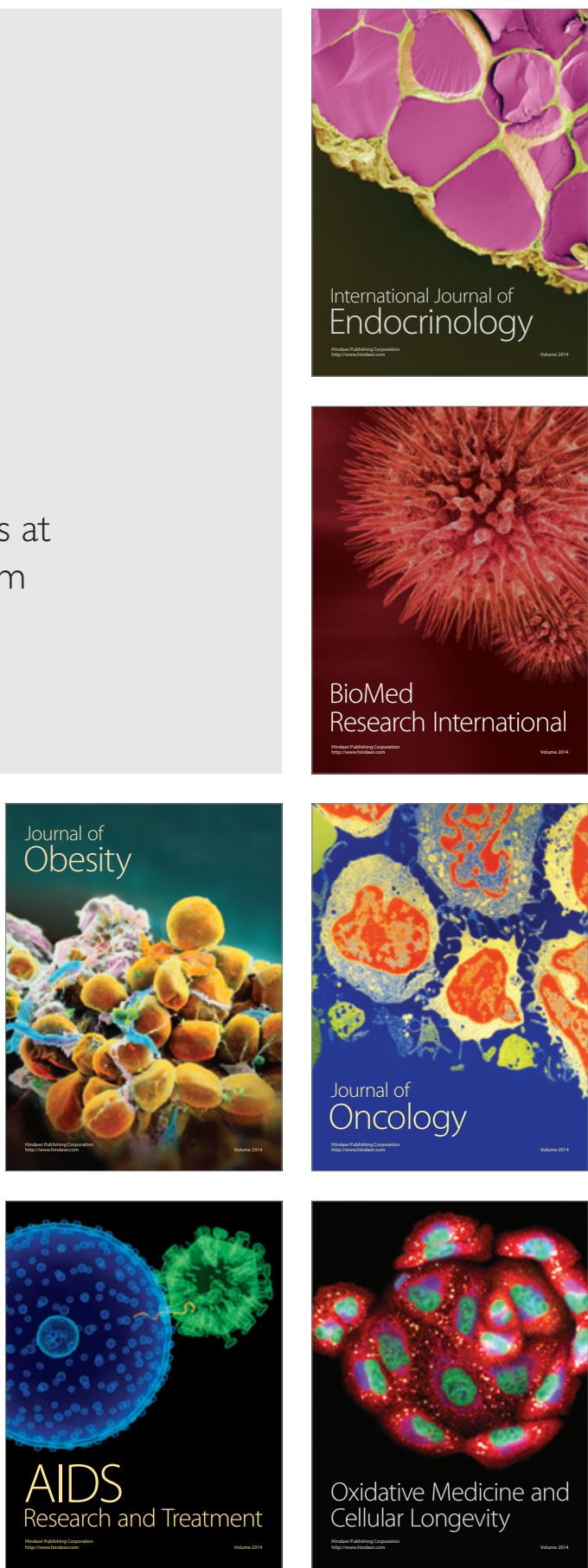